\title{
The embryonic Brachyury transcription factor is a novel biomarker of GIST aggressiveness and poor survival
}

\author{
Filipe Pinto ${ }^{1,2}$ - Nathalia C. Campanella ${ }^{3}$ Lucas F. Abrahão-Machado ${ }^{4}$. \\ Cristovam Scapulatempo-Neto ${ }^{3,4}$ - Antonio T. de Oliveira ${ }^{3,5}$ - Maria J. Brito ${ }^{6}$. \\ Raquel P. Andrade ${ }^{7}$ Denise P. Guimarães ${ }^{3,8}$ - Rui M. Reis ${ }^{1,2,3}$
}

Received: 19 December 2014/ Accepted: 29 April 2015/Published online: 21 May 2015

(C) The International Gastric Cancer Association and The Japanese Gastric Cancer Association 2015

\begin{abstract}
Background The T-box transcription factor Brachyury was recently reported to be upregulated and associated with prognosis in solid tumors. Here, we proposed to evaluate the potential use of Brachyury protein expression as a new prognostic biomarker in gastrointestinal stromal tumors (GIST).

Methods Brachyury protein expression was analyzed by immunohistochemistry in a cohort of 63 bona fide GIST patients. Brachyury expression profiles were correlated
\end{abstract}

Electronic supplementary material The online version of this article (doi:10.1007/s10120-015-0505-0) contains supplementary material, which is available to authorized users.

Rui M. Reis

ruireis.hcb@gmail.com

1 Life and Health Sciences Research Institute (ICVS), School of Health Sciences, University of Minho, Braga, Portugal

2 ICVS/3B's-PT Government Associate Laboratory, Braga, Guimarães, Portugal

3 Molecular Oncology Research Center, Barretos Cancer Hospital, Rua Antenor Duarte Villela, 1331, Barretos CEP 14784 400, Sao Paulo, Brazil

4 Department of Pathology, Barretos Cancer Hospital, Barretos, Sao Paulo, Brazil

5 Upper Digestive Surgery Department, Barretos Cancer Hospital, Barretos, Sao Paulo, Brazil

6 Department of Pathology, Hospital Garcia de Orta, Almada, Portugal

7 Regenerative Medicine Program, Department of Medicine and Biomedical Sciences, University of Algarve, Faro, Portugal

8 Department of Endoscopy, Barretos Cancer Hospital, Barretos, Sao Paulo, Brazil with patients' clinicopathological features and prognostic impact. Additionally, an in silico analysis was performed using the Oncomine database to assess Brachyury alterations at DNA and mRNA levels in GISTs.

Results We found that Brachyury was overexpressed in the majority $(81.0 \%)$ of primary GISTs. We observed Brachyury staining in the nucleus alone in $4.8 \%$ of cases, $23.8 \%$ depicted only cytoplasm staining, and $52.4 \%$ of cases exhibited both nucleus and cytoplasm immunostaining. The presence of Brachyury was associated with aggressive GIST clinicopathological features. Particularly, Brachyury nuclear (with or without cytoplasm) staining was associated with the presence of metastasis, while cytoplasm sublocalization alone was correlated with poor patient survival.

Conclusions Herein, we demonstrate that Brachyury is overexpressed in GISTs and is associated with worse outcome, constituting a novel prognostic biomarker and a putative target for GIST treatment.

Keywords Brachyury · GIST $\cdot$ Metastasis $\cdot$ Poor prognosis

\section{Introduction}

Gastrointestinal stromal tumors (GISTs) are the most frequent mesenchymal tumors of the gastrointestinal tract, representing 10-20 cases per million in the world [1-3]. GISTs present driver oncogenic mutations of receptor tyrosine kinases KIT and PDGFRA and, less frequently, of the BRAF signal transduction molecule [4-6]. The discovery that KIT-mutant GISTs respond positively to the tyrosine kinase inhibitor imatinib mesylate has significantly improved the prognosis of this disease [7-9]. In fact, about $85 \%$ of patients with 
metastatic GIST exhibited substantial clinical benefit from imatinib treatment [10]. The median survival of patients treated with the current therapy is about 5 years, and $34 \%$ of them survive more than 9 years [3]. However, despite all of these improvements, disease progression occurs in approximately $75 \%$ of the patients $[10,11]$. Several prognostic parameters are used in GIST management, such as tumor size, location, mitotic index and KIT/PDGFRA mutations, yet many GISTs still behave unpredictably. Thus, it is crucial to find new biomarkers for GIST prognosis.

The T-box transcription factor Brachyury plays a key role during early embryo gastrulation, a typical process of epithelial-mesenchymal transition (EMT) [12, 13]. Brachyury involvement in cancer was initially limited to chordomas, being currently its main etiological factor [14]. More recently, it has been associated with tumor aggressiveness in several types of cancer cells, ultimately promoting invasion and metastasis [15-22]. Our group has recently described Brachyury as a new and important marker of poor prognosis, cell invasion and metastasis in prostate cancer patients, where it was also associated with higher EMT and stemness expression profiles [19]. Taking into account the important role of Brachyury in tumorigenesis and the need for new biomarkers in GIST, we aimed to examine whether Brachyury immunostaining is associated with GIST prognosis and aggressiveness. Herein, we report that Brachyury is associated with GIST metastasis and patient outcome. Importantly, we suggest Brachyury as a new biomarker for GIST prognosis.

\section{Materials and methods}

\section{Tissue samples}

Paraffin-embedded tumor samples from 63 primary GISTs were obtained from the Pathology Department of Barretos Cancer Hospital, São Paulo, Brazil, and Garcia de Horta Hospital, Almada, Portugal. Samples were previously classified according to Fletcher and collaborators' criteria and risk group [23] and characterized immunohistochemically for CD117, S100, Ki67 and DOG1 as well as molecularly for KIT (exons 9, 11, 13, 17), PDGFRA (exons 12, 14, 18), BRAF (V600E) and TERT promoter mutations [24-26]. The cohort comprised $93.7 \%$ of CD117-positive cases, $71.1 \%$ of KIT, $18.3 \%$ of PDGFRA and $1.6 \%$ of TERT-mutated GISTs. Thirty-six $(57.1 \%)$ patients were male and $27(42.9 \%)$ female with a median age of 61 years (range 10-89). Clinicopathological characteristics available for GIST patients are the following: $4(7.6 \%)$ of 53 patients had very low Fletcher risk, 10/53 (18.9\%) low risk, 12/53 (22.6\%) intermediate risk and 27/53 (50.9\%) high risk; 24 (42.8\%) of 56 patients present metastasis at diagnosis. The diagnosis of metastasis was based on unequivocal imaging findings; $38(80.9 \%)$ of 47 patients received $\mathrm{R} 0,10.6 \%(5 / 47)$ received $\mathrm{R} 1$ and $8.5 \%(2 / 47)$ received R2 surgery. Twenty-seven $(48.2 \%)$ of 56 patients were treated with imatinib (25 patients with $400 \mathrm{mg} /$ daily and 2 with $800 \mathrm{mg} /$ daily). At the end of follow-up, $24.6 \%$ $(15 / 61)$ died because of the disease and $4.9 \%(3 / 61)$ because of unrelated causes; $42.6 \%$ of patients $(26 / 61)$ were alive without disease and $27.9 \%(17 / 61)$ had disease. The project was previously approved by the local ethics committee (no. 554/2011).

\section{Immunohistochemistry analysis}

For immunohistochemistry analyses, tissue microarray (TMA) blocks were performed, containing three representative areas of each GIST tissue (1 mm diameter core). Representative 4- $\mu$ m-thick sections were subjected to immunohistochemical analysis using the streptavidin-biotin peroxidase complex system (UltraVision Large Volume Detection System Anti-Polyvalent, HRP; LabVision Corp.), as previously described [19] (Supplementary Fig S1), using the primary antibody raised against Brachyury (sc-20109: Santa Cruz Biotechnology, Inc.) [16, 19, 27-29]. Tumor samples were evaluated for extension (percentage of cytoplasm-positive cells: 0 , negative; $1,<25 \%$ positive cells; 2 , $26-50 \%$ positive cells; $3,>50 \%$ positive cells) and intensity ( 0 , negative; 1 , weak; 2 , moderate; 3 , strong) of the immunoreactions. The score used for cytoplasm staining was the sum of the extension and the staining intensity. Samples with scores 0-2 were considered negative, and those with scores 3-6 were considered positive. Brachyury nuclear staining was also evaluated and considered negative $(<25 \%$ of the cells with positive nuclei staning) or positive ( $\geq 25 \%$ of the cells depicting nuclear staining). The final score of Brachyury staining was the combination of both cytoplasm and nuclear staining, negative (negative for both subcellular locations) and positive (positive for cytoplasm and/or nuclear staining).

\section{In silico microarray data analyses}

Brachyury expression was assessed in two data sets containing specific information for mRNA expression (Cho [30] and Bittner, non published data [31]) and in two data sets with information for DNA copy number variation (Barretina [32] and Berouklim [33]) in GIST samples extracted from the Oncomine database [31]. Brachyury expression is defined as $\log 2$ median-centered intensity values for each probe (206524_at, ILMN-1794551 and AI337100) and DNA copy number variation as Log2 copy number units (probe 06-166496598). Microarray coexpression studies in five GIST samples were extracted from Subramanian data set [34]. Microarray expression profiles 
were clustered by functional importance and signaling pathways using DAVID v6.7 bioinformatic tool (The Database for Annotation, Visualization and Integrated Discovery) [35, 36], as previously described [19].

\section{Statistical analyses}

Correlations between Brachyury expression and available clinicopathological data were performed using Pearson's chisquare test $\left(\chi^{2}\right.$-test). Cumulative survival probabilities were calculated using the Kaplan-Meier method. Differences between survival rates were tested using the log-rank test. Statistical analysis was performed using SPSS software for Windows, version 19.0. Simple comparisons between expression levels from the Oncomine database were analyzed by Student's t test using Prism GraphPad software (version 5.0a). The levels of significance in the statistical analysis are indicated as $* p<0.05, * * p<0.01$ or $* * * p<0.001$.

\section{Results}

\section{Brachyury is overexpressed in GISTs}

An immunohistochemistry analysis of Brachyury expression in a cohort of 63 GISTs was performed. Representative images of Brachyury staining are shown in Fig. 1. We found that
Brachyury is absent or expressed at very low levels in normal tissues (epithelial gastric cells) adjacent to tumor (Fig. 1a-i) and that $19.0 \%(12 / 63)$ of GISTs are negative for Brachyury (both nucleus and cytoplasm) (Fig. 1a, b-ii). In GIST-positive tissues $(81.0 \% ; n=51 / 63)$, Brachyury was found at the cytoplasm and/or nuclear level (Fig. 1a-iii, b-iv). Specifically, we found Brachyury staining only in the nucleus for $3 / 63$ (4.8\%) cases, 15/63 (23.8\%) only in the cytoplasm and 33/63 $(52.4 \%)$ in both the nucleus and cytoplasm (Fig. 1b). For statistical analysis, GIST tumors were classified into two groups: negative (negative for both cytoplasm and nuclear staining) vs. positive (positive for both cytoplasm and/or nuclear staining) or in three groups based on Brachyury subcellular localization: negative $(12 / 63 ; 19.1 \%)$ vs. cytosolic staining alone $(15 / 63 ; 23.8 \%)$ vs. nuclear staining (with or without cytoplasm staining: 36/63; $52.4 \%$ ) (Tables 1, 2).

\section{Brachyury nuclear sublocalization is associated with the presence of metastasis}

We further assessed the correlation of Brachyury staining with GIST clinicopathological and molecular features (Table 1,2). Using univariate analysis we found a statistically significant association between Brachyury staining and subcellular localization and PDGFRA mutation status ( $p=0.005$ and $p=0.003$, respectively; Table 1$)$. No significant association between Brachyury levels and other
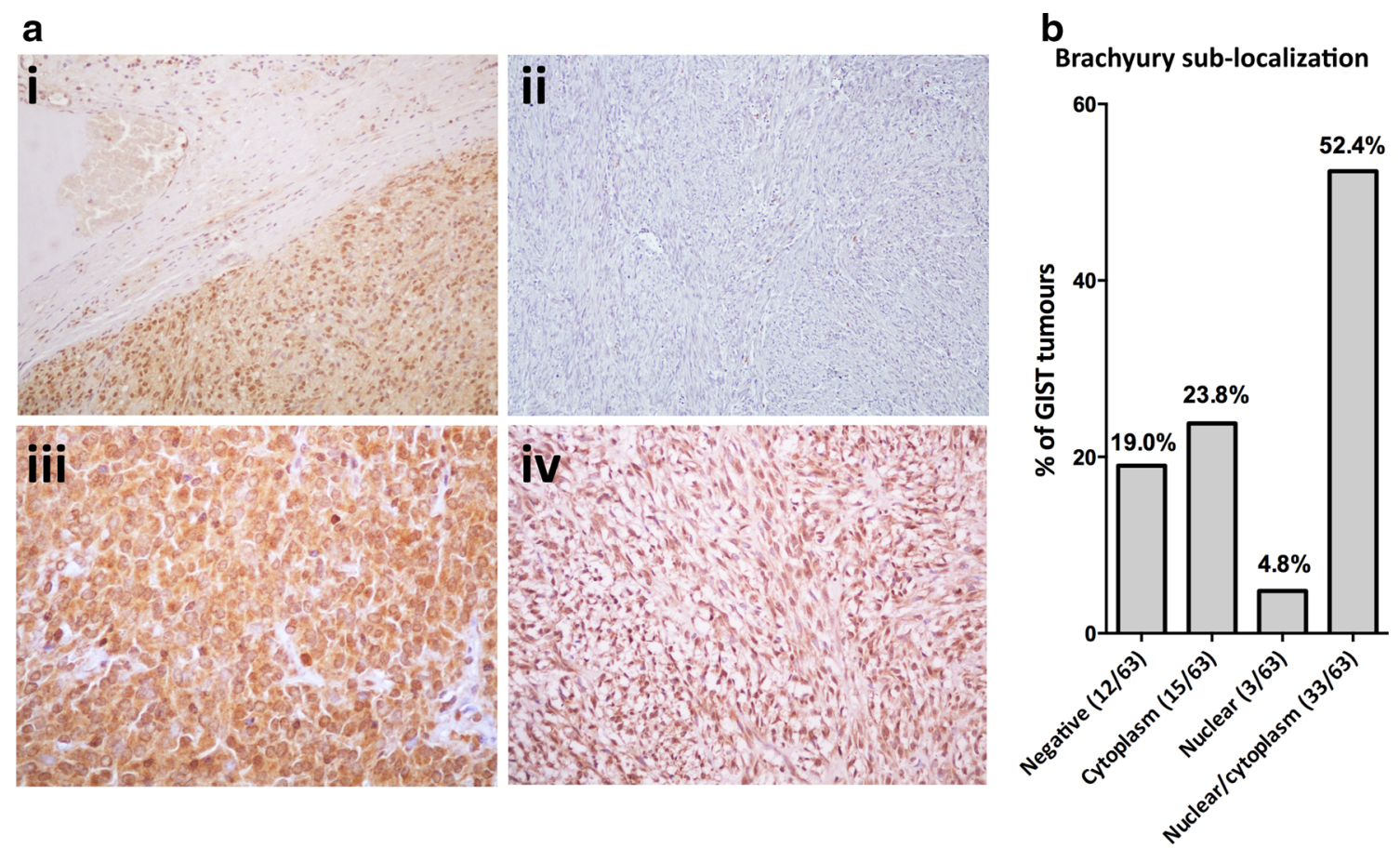

Fig. 1 Immunohistochemical analysis evidencing Brachyury overexpression in GISTs. a Negative expression in normal adjacent tissue ( $i$, left side) compared with GIST tissue ( $i$, right side); $i i$ a case of a GIST case negative for Brachyury. In Brachyury-positive GIST tissues it was possible to observe Brachyury expression in both the cytoplasm (iii) and/or nucleus (iv). Magnification: a $\times 100$; b $\times 200$; $\mathbf{c}$ and $\mathbf{d} \times 400$. b Graphic representation of the percentage of GIST cases stratified by Brachyury sublocalization 
Table 1 Correlation between Brachyury staining and subcellular localization with molecular features in GIST patients

\begin{tabular}{|c|c|c|c|c|c|c|c|c|}
\hline \multirow[t]{2}{*}{ Clinical parameters } & \multirow[t]{2}{*}{$n$} & \multicolumn{3}{|c|}{ Brachyury staining } & \multicolumn{4}{|c|}{ Brachyury subcellular localization } \\
\hline & & Negative (\%) & Positive (\%) & $p$ value & Negative (\%) & Only cytoplasm (\%) & $\begin{array}{l}\text { Nucleus (with or without } \\
\text { cytoplasm }(\%)\end{array}$ & $p$ value \\
\hline \multicolumn{9}{|l|}{ CD117 } \\
\hline Negative & 4 & $1(25.0)$ & $3(75.0)$ & 1.000 & $1(25.0)$ & $0(0.0)$ & $3(75.0)$ & 0.513 \\
\hline Positive & 59 & $11(18.6)$ & $48(81.4)$ & & $11(18.6)$ & $15(25.4)$ & $33(56.0)$ & \\
\hline \multicolumn{9}{|l|}{ DOG1 } \\
\hline Negative & 2 & $0(0.0)$ & $2(100.0)$ & 1.000 & $0(0.0)$ & $0(0.0)$ & $2(100.0)$ & 0.395 \\
\hline Positive & 51 & $11(21.5)$ & $40(78.4)$ & & $11(21.5)$ & $14(27.5)$ & $26(51.0)$ & \\
\hline \multicolumn{9}{|l|}{ S100 } \\
\hline Negative & 39 & $8(20.5)$ & $31(79.5)$ & 1.000 & $8(20.5)$ & $11(28.2)$ & $20(51.3)$ & 0.499 \\
\hline Positive & 4 & $0(0.0)$ & $4(100.0)$ & & $0(0.0)$ & $2(50.0)$ & $2(50.0)$ & \\
\hline \multicolumn{9}{|l|}{ TERT mutation } \\
\hline Wild-type & 62 & $12(19.4)$ & $50(80.6)$ & 1.000 & $12(19.4)$ & $15(24.1)$ & $35(56.5)$ & 0.683 \\
\hline Mutant & 1 & $0(0.0)$ & $1(100.0)$ & & $0(0.0)$ & $0(0.0)$ & $1(100.0)$ & \\
\hline \multicolumn{9}{|l|}{ KIT mutation } \\
\hline Wild-type & 16 & $6(37.5)$ & $10(62.5)$ & 0.069 & $6(37.5)$ & $2(12.5)$ & $8(50.0)$ & 0.125 \\
\hline Mutant & 43 & $6(14.0)$ & $37(86.0)$ & & $6(14.0)$ & $10(23.2)$ & $27(62.8)$ & \\
\hline \multicolumn{9}{|l|}{ PDGFRA mutation } \\
\hline Wild-type & 49 & $6(12.2)$ & $43(87.8)$ & $0.005^{*}$ & $6(12.2)$ & $13(26.5)$ & $36(61.3)$ & $0.003^{*}$ \\
\hline Mutant & 11 & $6(54.5)$ & $5(45.5)$ & & $6(54.5)$ & $0(0.0)$ & $5(45.5)$ & \\
\hline \multicolumn{9}{|c|}{ KIT/PDGFRA mutation } \\
\hline Wild-type & 6 & $0(0.0)$ & $6(100.0)$ & 0.333 & $0(0.0)$ & $3(50.0)$ & $3(50.0)$ & 0.144 \\
\hline Mutant & 54 & $12(22.2)$ & $42(77.8)$ & & $12(22.2)$ & $10(18.5)$ & $32(59.3)$ & \\
\hline
\end{tabular}

$* p<0.05$, statistically significant values

variables analyzed (KIT and TERT mutation status, and CD117, DOG1 and S100) was found (Table 1). Concerning the clinicopathological impact, we found that Brachyury in the nucleus was strongly associated with presence of metastasis ( $p=0.020$; Table 2$)$. No associations were found with the type of resection (R0 vs. R1 vs. R2) and with treatment (imatinib vs. no treatment) (data not shown).

\section{Brachyury association with GIST aggressiveness evidenced by in silico microarray analysis}

In silico analyses of Brachyury mRNA expression in GISTs were performed to extend and validate our findings at the protein level. Data were extracted from two microarray expression data sets available in Oncomine with more than two cases analyzed [31]. Brachyury was statistically upregulated in both data sets (Fig. 2a). In an attempt to understand if increased expression of Brachyury in GISTs could be due to gene amplification, we analyzed copy number alterations in two additional data sets (Barretina [32] and Beroukhim [33]). No Brachyury gene amplification was found in GIST cell lines, primary GISTs or GIST subtypes (Fig. 2b).
An analysis of genes coexpressed with Brachyury in Oncomine microarray data [31] was performed to identify putative partners and pathways associated with Brachyury in GISTs (Fig. 3). As shown in Fig. 3, genes coexpressed with Brachyury were functionally clustered in oncogenic pathways (MAPK, Wnt, PPAR, ErbB and TGF-beta signaling pathway). Moreover, a strong association with pathways involved in the cell metabolism/microenvironment was also identified (PPAR, insulin/IGF-1, adipocytokine signaling pathways, arginine, proline, alanine, aspartate and glutamate metabolism, panthothenate and CoA biosynthesis, biosynthesis of unsaturated fatty acids). This analysis suggests that Brachyury could promote GIST aggressiveness by regulating multiple oncogenic pathways.

Overexpression of Brachyury in the cytoplasm are predictive of poor prognosis

Regarding disease-specific survival (univariate analysis) and clinicopathological features, we found that lower survival was significantly associated with mixed subtype $(p=0.047)$ and Fletcher's risk malignancy ( $p=0.045)$ (data not shown). 
Table 2 Correlation between Brachyury staining and subcellular localization with clinicopathological features in GISTs

\begin{tabular}{|c|c|c|c|c|c|c|c|c|}
\hline \multirow[t]{2}{*}{ Clinical parameters } & \multirow[t]{2}{*}{$n$} & \multicolumn{3}{|c|}{ Brachyury staining } & \multicolumn{4}{|c|}{ Brachyury subcellular localization } \\
\hline & & $\begin{array}{l}\text { Negative } \\
(\%)\end{array}$ & $\begin{array}{l}\text { Positive } \\
(\%)\end{array}$ & $p$ value & $\begin{array}{l}\text { Negative } \\
(\%)\end{array}$ & $\begin{array}{l}\text { Only cytoplasm } \\
(\%)\end{array}$ & $\begin{array}{l}\text { Nucleus (with or } \\
\text { without cytoplasm) (\%) }\end{array}$ & $p$ value \\
\hline \multicolumn{9}{|l|}{ Age (years) } \\
\hline$<61$ & 27 & $4(14.8)$ & $23(85.2)$ & 0.531 & $4(14.8)$ & $4(14.8)$ & $19(70.4)$ & 0.174 \\
\hline$\geq 61$ & 36 & $8(22.2)$ & $28(77.8)$ & & $8(22.2)$ & $11(30.6)$ & $17(47.2)$ & \\
\hline \multicolumn{9}{|l|}{ Gender } \\
\hline Male & 36 & $8(22.2)$ & $28(77.8)$ & 0.531 & $8(22.2)$ & $6(16.7)$ & $22(61.1)$ & 0.290 \\
\hline Female & 27 & $4(14.8)$ & $23(85.2)$ & & $4(14.8)$ & $9(33.3)$ & $14(51.9)$ & \\
\hline \multicolumn{9}{|l|}{ Tumor local } \\
\hline Gastric (large bowel + stomach) & 31 & $8(25.8)$ & $23(74.2)$ & 0.199 & $8(25.8)$ & $4(12.9)$ & $19(61.3)$ & 0.219 \\
\hline Small bowel & 21 & $4(19.0)$ & $17(81.0)$ & & $4(19.0)$ & $6(28.6)$ & $11(52.4)$ & \\
\hline Other & 10 & $0(0.0)$ & $10(100.0)$ & & $0(0.0)$ & $4(40.0)$ & $6(60.0)$ & \\
\hline \multicolumn{9}{|l|}{ Cellular morphology } \\
\hline Epithelioid & 15 & $6(40.0)$ & $9(60.0)$ & 0.067 & $6(40.0)$ & $2(13.3)$ & $7(46.7)$ & 0.188 \\
\hline Spindle & 40 & $5(12.5)$ & $35(87.5)$ & & $5(12.5)$ & $11(27.5)$ & $24(60.0)$ & \\
\hline Mixed & 7 & $1(14.3)$ & $6(85.7)$ & & $1(14.3)$ & $1(14.3)$ & $5(71.4)$ & \\
\hline \multicolumn{9}{|l|}{ Risk grade (Fletcher) } \\
\hline Low (very low + low) & 14 & $2(14.3)$ & $12(85.7)$ & 1.000 & $2(14.3)$ & $4(28.6)$ & $8(57.1)$ & 0.919 \\
\hline High (intermediate + high) & 39 & $6(15.4)$ & $33(84.6)$ & & $6(15.4)$ & $9(23.1)$ & $24(61.5)$ & \\
\hline \multicolumn{9}{|l|}{ Tumor size $(\mathrm{cm})$} \\
\hline$<5$ & 18 & $5(27.8)$ & $13(72.2)$ & 0.482 & $5(27.8)$ & $5(27.8)$ & $8(44.4)$ & 0.502 \\
\hline$\geq 5$ & 42 & $7(16.7)$ & $35(83.3)$ & & $7(16.7)$ & $10(23.8)$ & $25(59.5)$ & \\
\hline \multicolumn{9}{|l|}{ Mitotic index (50CGA) } \\
\hline$\leq 5$ & 29 & $3(10.3)$ & $26(89.7)$ & 0.650 & $3(10.3)$ & $7(24.1)$ & $19(65.5)$ & 0.708 \\
\hline$>5$ & 16 & $3(18.8)$ & $13(81.5)$ & & $3(18.8)$ & $4(25.0)$ & $9(56.3)$ & \\
\hline \multicolumn{9}{|l|}{ Metastasis } \\
\hline Absent & 32 & $9(28.1)$ & $23(71.9)$ & 0.140 & $9(28.1)$ & $11(34.4)$ & $12(37.5)$ & $0.020 *$ \\
\hline Present & 24 & $3(12.5)$ & $21(87.5)$ & & $3(12.5)$ & $3(12.5)$ & $18(75.0)$ & \\
\hline \multicolumn{9}{|l|}{ Site of metastasis } \\
\hline Peritoneum & 4 & $1(25.0)$ & $3(75.0)$ & 0.123 & $1(25.0)$ & $1(25.0)$ & $2(50.0)$ & 0.315 \\
\hline Liver & 19 & $1(5.3)$ & $18(94.7)$ & & $1(5.3)$ & $3(15.8)$ & $15(78.9)$ & \\
\hline Others/Both & 2 & $1(50.0)$ & $1(50.0)$ & & $1(50.0)$ & $0(0.0)$ & $1(50.0)$ & \\
\hline \multicolumn{9}{|l|}{ Recurrence } \\
\hline No & 34 & $7(20.6)$ & $27(79.4)$ & 1.000 & $7(20.6)$ & $8(23.5)$ & $19(55.9)$ & 0.897 \\
\hline Yes & 11 & $2(18.2)$ & $9(81.8)$ & & $2(18.2)$ & $2(18.2)$ & 7 (63.6) & \\
\hline
\end{tabular}

$* p<0.05$, statistically significant values

Overall Brachyury overexpression exhibited a tendency to be associated with poor patient prognosis $(p=0.079$; Table 3; Fig. 4a). We then analyzed the prognostic impact of Brachyury subcellular localization in order to better understand the importance of Brachyury compartmentalization. We observed that all Brachyury-negative GIST patients were alive (follow-up $=44.9 \pm 37.5$ months), and there was a tendency for Brachyury cytoplasm staining to be associated with the status of GIST patients [alive without disease: $11.5 \%<$ alive with disease: $23.5 \%<$ dead due to disease: $40.0 \%$ ] (Table 3). Importantly, Brachyury positivity in the cytoplasm alone was associated with reduced disease-specific survival, nuclear (with or without cytoplasm)-positive cases present an intermediate survival, and the GIST negative cases have the best patient outcome ( $p=0.036$; Fig. $4 \mathrm{~b}$; Table 3 ). The low number of cases precluded multivariate analysis of the studied parameters.

\section{Discussion}

The treatment of GISTs was revolutionized by the introduction of imatinib, a potent KIT inhibitor, as the first option for KIT/PDGFRA-driven mutation and metastatic 
a

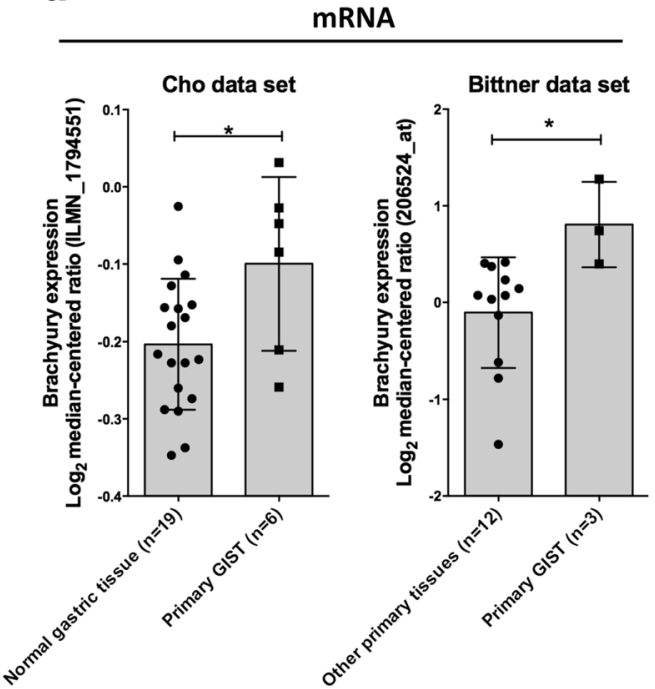

Fig. 2 In silico analysis of Brachyury expression and copy number variation from Oncomine database. a Scatter plot with bar (mean with $\mathrm{SD}$ ) for Brachyury mRNA expression. It is possible to observe that Brachyury is overexpressed in GIST samples compared with normal tissues (Cho data set) or other normal tissues [Bittner data set (other

a

DAVID Functional Annotation Clustering

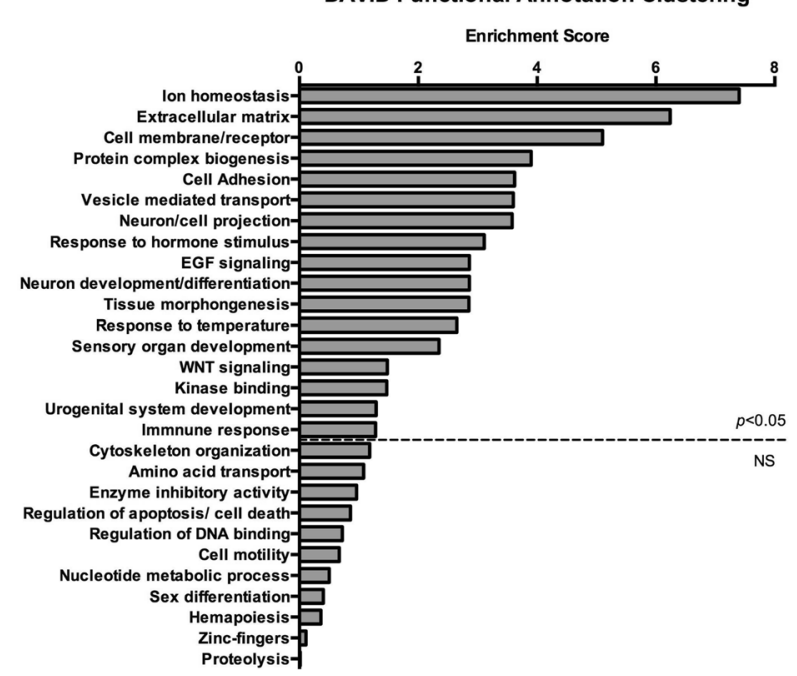

Fig. 3 Microarray expression analysis of genes coexpressed with Brachyury. a Microarray expression profiles of Brachyury coexpressed genes were clustered by functional role and signaling pathways using DAVID bioinformatics tool. Brachyury coexpressed genes were organized by their functional definition. Clusters with statistical significance and higher enrichment scores were associated

disease [37, 38]. However, a subset of patients develops imatinib-resistant GISTs and eventually progresses to more aggressive disease. Therefore, new prognostic biomarkers are needed. We previously showed that molecular alterations in RKIP [39] and MCT1 and its chaperone (CD147) [24] are associated with GIST poor overall survival, but do tissues: 5 normal colon, 1 lung, 1 spleen, 1 ovary, 1 abdomen, 1 bone and 2 with no data]. b Analysis of copy number variation of Brachyury in two different data sets. The Brachyury gene is not amplified or deleted in normal tissue and GISTs (Beroukhim data set) or in GIST subtypes (Barretina data set)

b

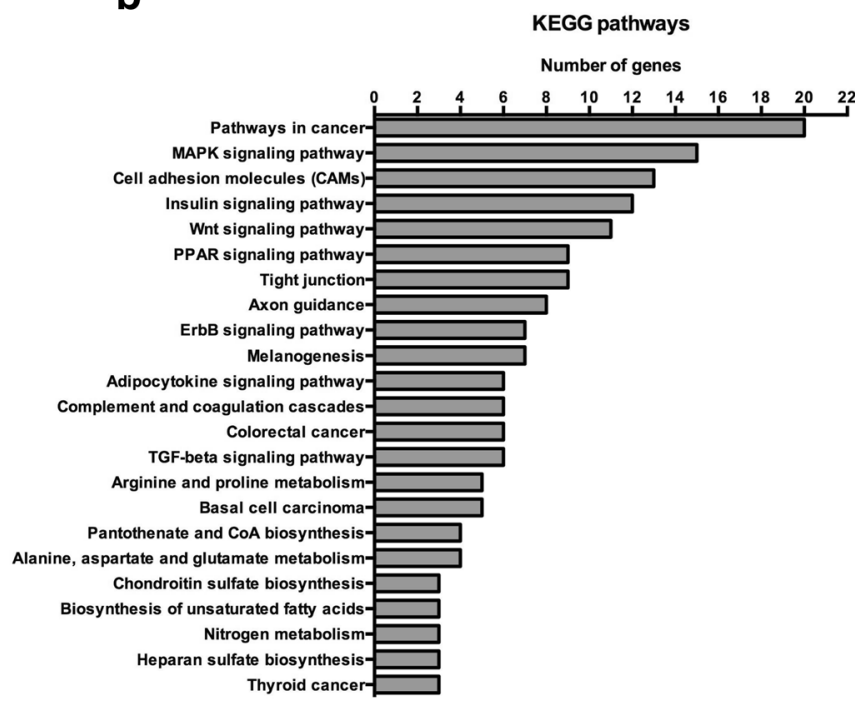

with tumor aggressiveness, microenvironment modulation and embryonic tissue development. b KEGG signaling pathway subanalysis. Pathways involved in tumor aggressiveness (MAPK, WNT, Erb, PPAR, TGF-beta signaling pathways) and tumor metabolism and invasion were the ones with a higher number of genes coexpressed with Brachyury. ${ }^{*} p<0.05$. NS non significant

not aid in predicting tumor resistance or metastatic disease, which can preclude patient treatment.

T-box transcription factor Brachyury was recently described to be overexpressed in several tumor types [17-20, 40, 41], playing an important role in EMT processes, metastasis and stem cell-like features [15-19, 41-43]. Due 
Table 3 Effect of Brachyury staining and subcellular localization on overall survival of GIST patients

\begin{tabular}{|c|c|c|c|c|c|c|c|c|}
\hline \multirow[t]{2}{*}{ Clinical parameters } & \multirow[t]{2}{*}{$n$} & \multicolumn{3}{|c|}{ Brachyury staining } & \multicolumn{4}{|c|}{ Brachyury subcellular localization } \\
\hline & & $\begin{array}{l}\text { Negative } \\
(\%)\end{array}$ & Positive (\%) & $p$ value & $\begin{array}{l}\text { Negative } \\
(\%)\end{array}$ & $\begin{array}{l}\text { Only cytoplasm } \\
(\%)\end{array}$ & $\begin{array}{l}\text { Nucleus (with or without } \\
\text { cytoplasm) }(\%)\end{array}$ & $p$ value \\
\hline \multicolumn{9}{|l|}{ Sensor status } \\
\hline Alive without cancer & 26 & $9(34.6)$ & $17(65.4)$ & $0.039 *$ & $9(34.6)$ & $3(11.5)$ & $14(53.8)$ & 0.095 \\
\hline Alive with cancer & 17 & $2(11.8)$ & $15(88.2)$ & & $2(11.8)$ & $4(23.5)$ & $11(64.7)$ & \\
\hline Dead due cancer & 15 & $0(0.0)$ & $15(100.0)$ & & $0(0.0)$ & $6(40.0)$ & $9(60.0)$ & \\
\hline Other $^{\mathrm{a}}$ & 3 & $1(33.3)$ & $2(66.7)$ & & $1(33.3)$ & $1(33.3)$ & $1(33.3)$ & \\
\hline Survival (months $\pm \mathrm{SD}$ ) & 55 & $11(\mathrm{NR})^{\mathrm{c}}$ & $44(50.5 \pm 9.5)^{b}$ & $0.079 *$ & $11(\mathrm{NR})^{\mathrm{c}}$ & $12(1.9 \pm 24.6)^{\mathrm{b}}$ & $32(66.1 \pm 12.5)^{\mathrm{b}}$ & $0.036^{*}$ \\
\hline
\end{tabular}

$S D$ standard deviation, $N R$ not reached

$* p<0.05$, statistically significant values

${ }^{\text {a }}$ Dead because of surgical complications

b Follow-up values calculated at $75 \%$ percentile

c All cases were censored

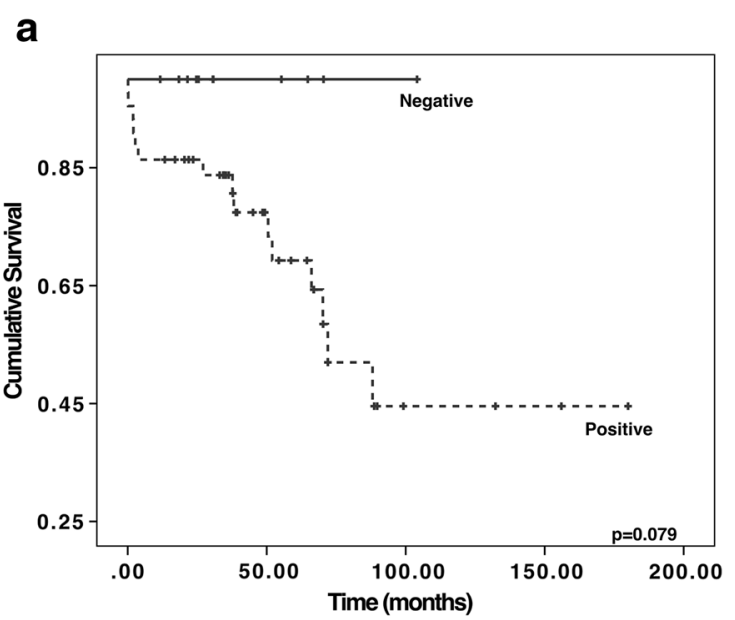

Fig. 4 Brachyury cytoplasm subcellular localization is a prognostic factor in GISTs. Kaplan-Meier curve (log-rank) of 44 patients with localized GIST based on Brachyury localization. a Kaplan-Meier

to its role in the EMT process and involvement in metastatic development in solid tumors [17, 19], Brachyury is positioned as a promising therapeutic target for advanced cancer patients [40, 44]. To our knowledge, this is the first study that investigates Brachyury immunostaining and its relevance as a novel marker of aggressiveness in GIST. In agreement with our previous study in prostate cancer [19], we found that Brachyury is overexpressed in GISTs, which may reflect a role in GIST biology. We previously described that Brachyury can be expressed in both the cytoplasm and nucleus of prostate carcinomas [19]. We also showed that cytoplasm Brachyury expression is remarkably related to more aggressive prostate carcinomas (higher Gleason scores), and nuclear expression is associated with

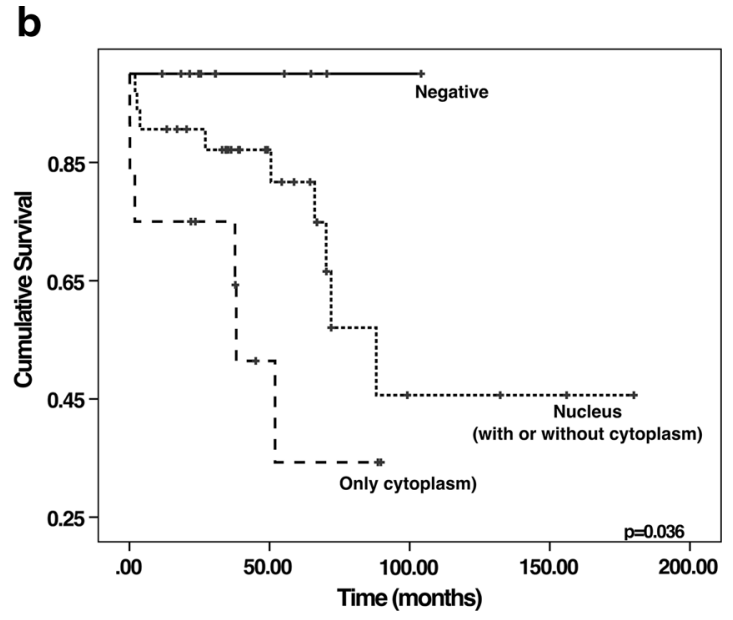

curve of GIST patients divided based on presence or absence of Brachyury. b Kaplan-Meier curve of GIST patients stratified based on Brachyury subcellular localization

invasive carcinomas, being preferentially expressed in prostate metastasis [19]. In the present study, we also show the importance of subcellular Brachyury location. In primary GISTs, nuclear sublocalization (with or without cytoplasm) relates with the presence of metastasis at diagnosis, in accordance with its role as a master regulator of EMT, being a therefore new putative biomarker of GIST aggressiveness. Further studies in a larger series, and in particular the comparison between primary and metastatic tissue of GISTs, are necessary to validate these findings.

It has been described that resected metastasis, primary and secondary GISTs that progress upon imatinib treatment reveal secondary KIT mutations as a common mechanism of resistance. However, a subset of GIST patients lacks 
KIT expression, indicating that KIT oncogenic programs have been supplanted by alternative oncogenic drivers yet to be unidentified $[45,46]$. Our data suggest that Brachyury expression and its effect on tumor progression are not related to KIT or PDGFRA mutations. In silico microarray coexpression analysis indicates that Brachyury could promote GIST aggressiveness and therapy resistance by modulating several biological processes, such as oncogenic pathways, tumor microenvironment and immune response. In fact, immune and metabolic pathways are gaining relevance in GIST [28], namely influencing patient response to imatinib therapy [47-49]. Further investigations on larger cohorts and functional studies will be required to validate these data.

The impact of Brachyury in poor prognosis has already been described for early stages of colorectal cancer [20], lung cancer [21], oral squamous cell carcinomas [17] and prostate cancer [19]. In our series of GISTs, we stratify GIST patients into three distinct groups with differential survival probabilities based on Brachyury subcellular localization. We found a significant correlation between Brachyury in the cytoplasm alone and worse prognosis, a group with intermediate prognosis corresponding to the presence of Brachyury in the nucleus (with or without cytoplasm) and a subset of patients with good prognosis lacking Brachyury expression.

A growing number of transcription-dependent and -independent functions have been described [50]. Although the role of Brachyury protein in the cytoplasm has yet to be determined, we hypothesize that: (1) it can interact with different partners in order to regulate oncogenic signaling pathways, probably because of post-translation regulation, as described for other transcription factors [50, 51]; (2) it could be a consequence of a dynamic process of protein shuttling between cytosol-nucleus; or (3) it could be a consequence of an enhanced translation process resulting in accumulation in the cytosol. These results, together with a recent study showing that Brachyury mediates tumor resistance to conventional cytotoxic therapies [22] and with the possibility that Brachyury-expressing tumor cells can be lysed via immunotherapy by Brachyury-based vaccines [40, 44, 52], highlight Brachyury as a promising therapeutic target for cancer treatment, probably in combination with other drugs, such as imatinib.

\section{Conclusion}

In the present study, we assessed Brachyury immunostaining in GIST for the first time. Our results highlight the relevance of Brachyury in GIST aggressiveness, pointing to a potential novel prognostic biomarker and therapeutic target.
Acknowledgments This study was partially supported by the ICVS internal research funds of the participating authors and $\mathrm{CNPq}$ Universal (476192/2013-7) for RMR. FP received a doctoral fellowship from the FCT (SFRH/BD/81369/2011), and NCC is a recipient of an FAPESP doctoral fellowship (2013/25787-3).

\section{References}

1. Corless CL, Barnett CM, Heinrich MC. Gastrointestinal stromal tumours: origin and molecular oncology. Nat Rev Cancer. 2011;11:865-78

2. Miettinen M, El-Rifai W, Sobin L, Lasota J. Evaluation of malignancy and prognosis of gastrointestinal stromal tumors: a review. Hum Pathol. 2002;33:478-83.

3. Doyle LA, Hornick JL. Gastrointestinal stromal tumours: from KIT to succinate dehydrogenase. Histopathology. 2014;64:53-67.

4. Heinrich MC, Corless CL, Duensing A, McGreevey L, Chen CJ, Joseph N, et al. PDGFRA activating mutations in gastrointestinal stromal tumors. Science. 2003;299:708-10.

5. Hirota S, Isozaki K, Moriyama Y, Hashimoto K, Nishida T, Ishiguro $\mathrm{S}$, et al. Gain-of-function mutations of c-kit in human gastrointestinal stromal tumors. Science. 1998;279:577-80.

6. Martinho O, Gouveia A, Viana-Pereira M, Silva P, Pimenta A, Reis RM, et al. Low frequency of MAP kinase pathway alterations in KIT and PDGFRA wild-type GISTs. Histopathology. 2009;55:53-62.

7. Doyle LA, Hornick JL. Gastrointestinal stromal tumours: from KIT to succinate dehydrogenase. Histopathology. 2014;64:53-67.

8. Campanella NC, de Oliveira AT, Scapulatempo-Neto C, Guimarães DP, Reis RM. Biomarkers and novel therapeutic targets in gastrointestinal stromal tumors (GISTs). Recent Pat Anticancer Drug Discov. 2013;8:288-97.

9. Joensuu H, Hohenberger P, Corless CL. Gastrointestinal stromal tumour. Lancet. 2013;382:973-83.

10. Antonescu CR, Besmer P, Guo T, Arkun K, Hom G, Koryotowski $\mathrm{B}$, et al. Acquired resistance to imatinib in gastrointestinal stromal tumor occurs through secondary gene mutation. Clin Cancer Res. 2005;11:4182-90.

11. Blanke CD, Demetri GD, von Mehren M, Heinrich MC, Eisenberg B, Fletcher JA, et al. Long-term results from a randomized phase II trial of standard- versus higher-dose imatinib mesylate for patients with unresectable or metastatic gastrointestinal stromal tumors expressing KIT. J Clin Oncol. 2008;26:620-5.

12. Showell C, Binder O, Conlon FL. T-box genes in early embryogenesis. Dev Dyn. 2004;229:201-18.

13. Technau U, Scholz CB. Origin and evolution of endoderm and mesoderm. Int J Dev Biol. 2003;47:531-9.

14. Vujovic S, Henderson S, Presneau N, Odell E, Jacques TS, Tirabosco R, et al. Brachyury, a crucial regulator of notochordal development, is a novel biomarker for chordomas. J Pathol. 2006;209:157-65.

15. Fernando RI, Castillo MD, Litzinger M, Hamilton DH, Palena C. IL-8 signaling plays a critical role in the epithelial-mesenchymal transition of human carcinoma cells. Cancer Res. 2011;71:5296-306.

16. Fernando RI, Litzinger M, Trono P, Hamilton DH, Schlom J, Palena C. The T-box transcription factor Brachyury promotes epithelial-mesenchymal transition in human tumor cells. J Clin Invest. 2010;120:533-44.

17. Imajyo I, Sugiura T, Kobayashi Y, Shimoda M, Ishii K, Akimoto $\mathrm{N}$, et al. T-box transcription factor Brachyury expression is correlated with epithelial-mesenchymal transition and lymph node metastasis in oral squamous cell carcinoma. Int $\mathrm{J}$ Oncol. 2012;41:1985-95. 
18. Roselli M, Fernando RI, Guadagni F, Spila A, Alessandroni J, Palmirotta R, et al. Brachyury, a driver of the epithelial-mesenchymal transition, is overexpressed in human lung tumors: an opportunity for novel interventions against lung cancer. Clin Cancer Res. 2012;18:3868-79.

19. Pinto F, Pértega-Gomes N, Pereira MS, Vizcaíno JR, Monteiro P, Henrique RM, et al. T-box transcription factor Brachyury is associated with prostate cancer progression and aggressiveness. Clin Cancer Res. 2014;15(20):4949-61.

20. Kilic N, Feldhaus S, Kilic E, Tennstedt P, Wicklein D, Rv Wasielewski, et al. Brachyury expression predicts poor prognosis at early stages of colorectal cancer. Eur J Cancer. 2011;47:1080-5.

21. Haro A, Yano T, Kohno M, Yoshida T, Koga T, Okamoto T, et al. Expression of Brachyury gene is a significant prognostic factor for primary lung carcinoma. Ann Surg Oncol. 2013; doi:10.1245/s10434-013-2914-9.

22. Huang B, Cohen JR, Fernando RI, Hamilton DH, Litzinger MT, Hodge JW, et al. The embryonic transcription factor Brachyury blocks cell cycle progression and mediates tumor resistance to conventional antitumor therapies. Cell Death Dis. 2013;4:e682.

23. Fletcher CD, Berman JJ, Corless C, Gorstein F, Lasota J, Longley BJ, et al. Diagnosis of gastrointestinal stromal tumors: a consensus approach. Hum Pathol. 2002;33:459-65.

24. de Oliveira AT, Pinheiro C, Longatto-Filho A, Brito MJ, Martinho $\mathrm{O}$, Matos $\mathrm{D}$, et al. Co-expression of monocarboxylate transporter 1 (MCT1) and its chaperone (CD147) is associated with low survival in patients with gastrointestinal stromal tumors (GISTs). J Bioenerg Biomembr. 2012;44:171-8.

25. de Oliveira AT, Reis RM, Afonso J, Martinho O, Matos D, Carvalho AL, et al. Lymphangiogenic VEGF-C and VEGFR-3 expression in genetically characterised gastrointestinal stromal tumours. Histol Histopathol. 2011;26:1499-507.

26. Campanella NC, Celestino R, Pestana A, Scapulatempo-Neto C, de Oliveira AT, Brito MJ, et al. Low frequency of TERT promoter mutations in gastrointestinal stroma tumors (GISTs). Eur J Hum Genet. 2014; doi:10.1038/ejhg.2014.195.

27. Toivonen S, Lundin K, Balboa D, Ustinov J, Tamminen K, Palgi $\mathrm{J}$, et al. Activin A and Wnt-dependent specification of human definitive endoderm cells. Exp Cell Res. 2013;319:2535-44.

28. Stacchiotti S, Casali PG, Lo Vullo S, Mariani L, Palassini E, Mercuri M, et al. Chordoma of the mobile spine and sacrum: a retrospective analysis of a series of patients surgically treated at two referral centers. Ann Surg Oncol. 2010;17:211-9.

29. Roukens MG, et al. BMP4 promotes EMT and mesodermal commitment in human embryonic stem cells via SLUG and MSX2. Nature. 2008;28:2342-57.

30. Cho JY, Lim JY, Cheong JH, Park YY, Yoon SL, Kim SM, et al. Gene expression signature-based prognostic risk score in gastric cancer. Clin Cancer Res. 2011;17:1850-7.

31. Oncomine. Ann Arbor (MI): Compendia bioscience. (C) 2007-2010 [cited 2014 Jan 27]. Available from: https://www. oncomine.org.

32. Barretina J, Taylor BS, Banerji S, Ramos AH, Lagos-Quintana M, Decarolis PL, et al. Subtype-specific genomic alterations define new targets for soft-tissue sarcoma therapy. Nat Genet. 2010;42:715-21.

33. Beroukhim R, Mermel CH, Porter D, Wei G, Raychaudhuri S, Donovan J, et al. The landscape of somatic copy-number alteration across human cancers. Nature. 2010;463:899-905.

34. Subramanian S, West RB, Marinelli RJ, Nielsen TO, Rubin BP, Goldblum JR, et al. The gene expression profile of extraskeletal myxoid chondrosarcoma. J Pathol. 2005;206:433-44.

35. da Huang W, Sherman BT, Lempicki RA. Systematic and integrative analysis of large gene lists using DAVID bioinformatics resources. Nat Protoc. 2009;4:44-57.
36. da Huang W, Sherman BT, Lempicki RA. Lempicki, Bioinformatics enrichment tools: paths toward the comprehensive functional analysis of large gene lists. Nucleic Acids Res. 2009;37:1-13.

37. Demetri GD, von Mehren M, Blanke CD, Van den Abbeele AD, Eisenberg B, Roberts PJ, et al. Efficacy and safety of imatinib mesylate in advanced gastrointestinal stromal tumors. $\mathrm{N}$ Engl J Med. 2002;347:472-80.

38. Heinrich MC, Owzar K, Corless CL, Hollis D, Borden EC, Fletcher $\mathrm{CD}$, et al. Correlation of kinase genotype and clinical outcome in the North American Intergroup Phase III Trial of imatinib mesylate for treatment of advanced gastrointestinal stromal tumor: CALGB 150105 Study by Cancer and Leukemia Group B and Southwest Oncology Group. J Clin Oncol. 2008;26:5360-7.

39. Martinho O, Gouveia A, Silva P, Pimenta A, Reis RM, Lopes JM. Loss of RKIP expression is associated with poor survival in GISTs. Virchows Arch. 2009;455:277-84.

40. Palena C, Polev DE, Tsang KY, Fernando RI, Litzinger M, Krukovskaya LL, et al. The human T-box mesodermal transcription factor Brachyury is a candidate target for T-cell-mediated cancer immunotherapy. Clin Cancer Res. 2007;13:2471-8.

41. Shimoda M, Sugiura T, Imajyo I, Ishii K, Chigita S, Seki K, et al. The T-box transcription factor Brachyury regulates epithelialmesenchymal transition in association with cancer stem-like cells in adenoid cystic carcinoma cells. BMC Cancer. 2012;12:377.

42. Larocca C, Cohen JR, Fernando RI, Huang B, Hamilton DH, Palena C. An autocrine loop between TGF-betal and the transcription factor brachyury controls the transition of human carcinoma cells into a mesenchymal phenotype. Mol Cancer Ther. 2013;12:1805-15.

43. Sarkar D, Shields B, Davies ML, Müller J, Wakeman JA. BRACHYURY confers cancer stem cell characteristics on colorectal cancer cells. Int J Cancer. 2012;130:328-37.

44. Hamilton DH, Litzinger MT, Jales A, Huang B, Fernando RI, Hodge JW, et al. Immunological targeting of tumor cells undergoing an epithelial-mesenchymal transition via a recombinant brachyury-yeast vaccine. Oncotarget. 2013;4:1777-90.

45. Bauer S, Hartmann JT, de Wit M, Lang H, Grabellus F, Antoch $\mathrm{G}$, et al. Resection of residual disease in patients with metastatic gastrointestinal stromal tumors responding to treatment with imatinib. Int J Cancer. 2005;117:316-25.

46. Simon S, Grabellus F, Ferrera L, Galietta L, Schwindenhammer B, Mühlenberg T, et al. DOG1 regulates growth and IGFBP5 in gastrointestinal stromal tumors. Cancer Res. 2013;73:3661-70.

47. Cullinane C, Dorow DS, Kansara M, Conus N, Binns D, Hicks $\mathrm{RJ}$, et al. An in vivo tumor model exploiting metabolic response as a biomarker for targeted drug development. Cancer Res. 2005;65:9633-6.

48. Holdsworth $\mathrm{CH}$, Badawi RD, Manola JB, Kijewski MF, Israel DA, Demetri GD, et al. CT and PET: early prognostic indicators of response to imatinib mesylate in patients with gastrointestinal stromal tumor. AJR Am J Roentgenol. 2007;189:W324-30.

49. Rusakiewicz S, Semeraro M, Sarabi M, Desbois M, Locher C, Mendez R, et al. Immune infiltrates are prognostic factors in localized gastrointestinal stromal tumors. Cancer Res. 2013;73:3499-510.

50. Lau E, Ronai ZA. ATF2-at the crossroad of nuclear and cytosolic functions. J Cell Sci. 2012;125:2815-24.

51. Green DR, Kroemer G. Cytoplasmic functions of the tumour suppressor p53. Nature. 2009;458:1127-30.

52. Hamilton DH, Litzinger MT, Fernando RI, Huang B, Palena C. Cancer vaccines targeting the epithelial-mesenchymal transition: tissue distribution of brachyury and other drivers of the mesenchymal-like phenotype of carcinomas. Semin Oncol. 2012;39:358-66. 